\title{
Formation and degeneration of scaled capillary notochaetae in Owenia fusiformis Delle Chiaje, 1844 (Oweniidae, Annelida)
}

\author{
Julian Müller ${ }^{1}$ (D) $\cdot$ Thomas Bartolomaeus $^{1}$ (D) Ekin Tilic ${ }^{1,2}$ (D)
}

Received: 21 August 2021 / Revised: 16 November 2021 / Accepted: 22 November 2021 / Published online: 13 December 2021

(c) The Author(s) 2021

\begin{abstract}
Phylotranscriptomic studies of the past decade have repeatedly placed Oweniidae together with Magelonidae, as the sister group to remaining annelids. This newly established placement clearly makes them a key-lineage for understanding annelid evolution and morphology. One of the most prominent morphological features of all annelids are their chaetae. The arrangement and formation process (chaetogenesis) of these chitinous bristles have been studied extensively in hooked chaetae that are arranged in rows. However, the information on other types of chaetae is still scarce. In this study, we investigated the scaled capillary notochaetae of Owenia fusiformis, looking both into the formation process that causes the scaly surface ornamentation and into their arrangement within tight bundles. Our results demonstrate the incredible plasticity of chaetogenesis that allows forming a vast array of three-dimensional structures. The capillary chaetae of Owenia fusiformis are unique in lacking an enamel coating and the scales covering the apical surface of each chaeta are formed by a single microvillus of the chaetoblast. Furthermore, the bundle of chaetae has a peripherally located formative site and a central degenerative site and it appears to result from a secondary curling of the chaetal sac.
\end{abstract}

Keywords Chaetogenesis · Ultrastructure $\cdot$ Electron-microscopy $\cdot$ Formative site

\section{Introduction}

Oweniidae is a fascinating clade of tube-dwelling annelids, with a history of problematic phylogenetic placement (Bartolomaeus et al. 2005; Rouse and Fauchald 1997; Rousset et al. 2007; Struck et al. 2007). In the past decade, however, independent phylotranscriptomic studies have repeatedly recovered Oweniidae as the sister group to Magelonidae, and this clade as sister group to all other annelids (Andrade et al. 2015; Struck 2019; Weigert et al. 2014; Weigert and Bleidorn 2016). This new-found placement clearly makes Oweniidae a key lineage to understand annelid evolution and has garnered them well-deserved attention. In recent years, there has been a proliferation in morphological studies looking into oweniidan development (Carrillo-Baltodano et al. 2021), nervous system (Beckers et al. 2019; Helm et al.

Julian Müller

jmueller@evolution.uni-bonn.de

1 Institute of Evolutionary Biology, University of Bonn, Bonn, Germany

2 Department of Biology, Marine Biological Section, University of Copenhagen, Copenhagen, Denmark
2016) and parapodial glandular organs (Rimskaya-Korsakova et al. 2020). One of the most characteristic morphological features of all annelids are their chaetae (Hausen 2005). These chitinous bristles are not only important anatomical features for taxonomic purposes but the detailed study of their development has revealed a set of valuable characters that allows testing previously established homology hypotheses (Bartolomaeus 1998; Tilic et al. 2015a; Tilic and Bartolomaeus 2016). All these make a comprehensive study on chaetae in oweniids of particular interest.

The cellular machinery that gives rise to these complex and morphologically diverse structures is intricate and involves the interplay of a few cells located within an epidermal chaetal follicle. Multiple chaetal follicles together form a chaetal sac. The cell at the base of a follicle is the chaetoblast and it is characterized by apically protruding dynamic microvilli that form the template of the developing chaeta (O'Clair and Cloney 1974). As the chitinous material secreted around the changing microvillar template, it polymerizes the chaeta forms.

Majority of studies investigating chaetal ultrastructure and development in annelids have been on hooked chaetae (Bartolomaeus 1995, 2002; Bartolomaeus and Meyer 
1997; Hausen and Bartolomaeus 1998; Schweigkofler et al. 1998; Tilic et al. 2014). Oweniidae also have large patches of hooked chaetae in their neuropodia, and their ultrastructure and formation process have already been studied in detail by Meyer and Bartolomaeus (1996). In the notopodia, however, there are bundles of long capillary chaetae with a scaly surface. Recently, it has been shown that ornamentations that adorn the surface of a chaeta can be part of the enamel coating and are formed by the follicle cells, and not by the microvilli of the chaetoblast (Tilic et al. 2021a, 2021b). In this paper, we describe the ultrastructure and formation of scaled capillary chaetae in Owenia fusiformis Delle Chiaje 1844 that also have superficially similar surface ornamentations.

Chaetal formation in annelids often occurs in a restricted site located within the chaetal sac. The current hypothesis on the plesiomorphic condition in annelids is a single ventral formative site for the notochaetae and a single dorsal formative site for the neurochaetae (Hausen 2005; Hausen and Bartolomaeus 1998; Kolbasova et al. 2014; Schweigkofler et al. 1998). However, this is mainly based on studies on taxa within Sedentaria that mostly show chaetae arranged in rows. There are several exceptions to this pattern especially within Errantia (Tilic et al. 2014, 2019), in Amphinomida (Tilic et al. 2017), but also within Sedentaria (Hausen and Bartolomaeus 1998). The arrangement of chaetae within a chaetal sac most likely affects the position and number of formative sites. For this reason, the results we present in this paper on the chaetal topology within the notopodial bundles in Oweniidae help establish a baseline which will be crucial for a future broad-scale comparison.

\section{Materials and methods}

\section{Specimens}

All examined specimens of Owenia fusiformis Delle Chiaje, 1844 have been collected at the Bay of Pouldohan (Trégunc, Brittany, France) during low tide in July 2018 and kept in the aquarium of the Institute for Evolutionary Biology and Ecology at the University of Bonn. The animals were removed carefully from their sediment tubes before fixation.

\section{Micro-computed tomography $(\mu \mathrm{CT})$}

After fixation with $2.5 \%$ glutaraldehyde buffered in $0.05 \mathrm{M}$ phosphate $0.3 \mathrm{M} \mathrm{NaCl}$ saline for $1 \mathrm{~h}$ at room temperature, the specimen was transferred to $70 \%$ ethanol via an ascending ethanol series and finally stored in a phosphotungstic acid solution ( $0.3 \%$ PTA in $70 \%$ ethanol) for one week. The specimen was scanned in 70\% ethanol using a SkyScan 1272 $\mu \mathrm{CT}$ system (Bruker) $\mu \mathrm{CT}$ scanner at $2.7 \mu \mathrm{m}$ resolution. The data were reconstructed with Nrecon (Bruker) and the resulting image stack was processed using ImageJ (Schindelin et al., 2012). The 3D surface rendering was obtained using Drishti 2.6.5 (Limaye 2012). The entire $\mu \mathrm{CT}$ dataset for $O$. fusiformis is published together with this paper and is available under: https://doi.org/10.5281/zenodo.5222921.

\section{Light microscopy and transmission electron microscopy}

The fixation process was the same as for the $\mu \mathrm{CT}$ specimen except for adding ruthenium red to the fixative. A postfixation with $1 \% \mathrm{OsO}_{4}$ buffered in $0.05 \mathrm{M}$ phosphate $0.3 \mathrm{M}$ $\mathrm{NaCl}$ saline at $4{ }^{\circ} \mathrm{C}$ for 30 min was performed. Afterwards, the samples were dehydrated through an ascending acetone series followed by embedding them in araldite. All samples were sectioned sagitally. Semi-thin sections of $0.5 \mu \mathrm{m}$ were placed on object slides and stained with toluidine blue. They were studied and photographed with a microscope (BX-51, Olympus) equipped with an Olympus CC12 camera and the dot.slide 2.2 scanning system. Ultra-thin sections of $70 \mathrm{~nm}$ were transferred to Formvar-covered, singer-slot copper grids and stained with $2 \%$ uranyl acetate and $2.6 \%$ lead citrate in an automated TEM stainer (QG-3100, Boeckeler Instruments). They were analyzed and photographed with a transmission electron microscope (TEM; EM 10CR, ZEISS) with phosphor imaging plates (Ditabis).

\section{Confocal laser scanning microscopy}

The specimen was fixed in 4\% paraformaldehyde for $1 \mathrm{~h}$ and stored afterwards in 0.1 M PBS (phosphate buffered with saline) containing $0.01 \% \mathrm{NaN}_{3}$. Single segments were separated from each other by dissection and permeabilized in four 5-min changes of PBS with $0.1 \%$ Triton X-100 (Fisher Scientific). After overnight staining in $4{ }^{\circ} \mathrm{C}$ with TRITC phalloidin at a dilution of 1:100, the segments were rinsed in several changes of PBS with $0.1 \%$ Triton of up to $10 \mathrm{~min}$ and one $10 \mathrm{~min}$ rinse in PBS without Triton. Then, the samples were dehydrated in an ascending series of isopropanol and cleared in three 15 min changes of Murray's Clear (BABB, benzyl alcohol, benzyl benzoate). Finally, the samples were investigated using the confocal laser scanning microscope system (CLSM; TCS SPE, Leica). Z-projections were obtained using ImageJ.

\section{Scanning electron microscopy}

Fixation was performed as for the $\mu \mathrm{CT}$ specimen. After dehydration with an ascending acetone series, the samples were critical point dried with $\mathrm{CO}_{2}$ using a critical point dryer (CPD 030, BAL-TEC). Afterwards, they were coated with gold (SCD 005, BAL-TEC), stuck on metal plates and 
examined with a scanning electron microscope (SEM; FEI Verios 460L).

\section{Results}

\section{Chaetal arrangement and formative sites}

Anatomically, Owenia fusiformis can be subdivided in three distinct parts (Fig. 1A). First, the prostomium and peristomium form the tentacle crown, serving as feeding apparatus. The following three segments are fused, often designated as "thorax" (Watson 1901). Each of them bears two laterally oriented bundles of capillary chaetae. All subsequent segments form the last part, the "abdomen", showing a constant anatomy, which leads to the repetitive body plan typical for annelids. In this major part of the body, only the anterior margins of its extraordinarily long segments are equipped with chaetae (Fig. 1A). Neither noto- nor neurochaetae are associated to some kind of a parapodial protrusion (Figs. 1A, B, 2A).

The neurochaetae, representing bidentate hooks, are arranged in dense patches of extraordinarily high numbers. Both sides combined, these patches cover almost the entire circumference of the worm (Figs. 1A, 2A). The hooks are formed at the dorsal margin of the patches and move ventrally during growth (Fig. 2B).

The notopodial capillary chaetae are restricted to the very dorsal part of the chaetal margins of the segments (Figs. 1A, $2 \mathrm{~A})$. They are arranged in a compact, spirally packed and cone-shaped bundle, consisting of 40-60 chaetae and protruding approximately $250 \mu \mathrm{m}$ outside the body surface with an angle of nearly $90^{\circ}$ (Figs. 1A-C, 2). Histological sections confirm the impression of a compact arrangement with all chaetae of a bundle being formed within one single oval to circular chaetal sac (Fig. 1D). Even the very few notochaetae of the most posterior, and therefore youngest, segment are already organized as a bundle without any recognizable order of formation.

Newly formed chaetae can be distinguished from old ones, because they do not extend beyond the cuticle and/ or their basis is located closer to the surface (Fig. 3B-E). Furthermore, the basal part of young chaetae is characterized by a strong signal of phalloidin labelling the f-actin in the chaetoblast's apical dynamic microvilli, which are highly active during chaetogenesis (Fig. 2C-E). These young chaetae could only be found in the periphery of the chaetal sacs without any further topographical specification (Fig. 3B-E). The number of young chaetae within a single chaetal sac varies between 0 and 7 (Figs. 1, 2, 3). Their number is neither related to the size of the chaetal sacs nor to the total number of chaetae per bundle or the position of the respective segment within the animal. The diameter of newly formed chaetae does not differ from that of the others (Fig. 3B-D).

In contrast to formation, degeneration of capillary chaetae in $O$. fusiformis takes place in the center of a chaetal sac. Degenerating chaetae and, along with them, degenerating follicles can be easily identified by their extraordinarily wide follicle filled with some lighter grey amorphous mass (Fig. 3B). The chaeta itself becomes shorter during degeneration and their basal section is located closer to the surface of the animal so that degenerating chaetae and young chaetae are topologically hard to discriminate, except for their position within the chaetal sac. TEM data of a chaetal degeneration, however, show a thin, honeycomb-like chitinous meshwork with partially dissolved canals at its periphery (Fig. 3F). Some of the canals of the chaeta are filled with cellular protrusions of irregular ultrastructural composition. Towards the base of the chaeta, parts of the meshwork in the center of the chaetae begin to dissolve, while the disintegration of the peripheral canals continues. This causes the chaeta to decrease in diameter and taper towards its base (Fig. 3G-I). Even deeper, parts of a cell lying underneath the chaeta, expand into the partially dissolved meshwork (Fig. 3H, I). This cell is filled with lysosomes and probably is the chaetoblast that once formed the chaeta.

Chaetae are formed in the periphery of the bundle and shift towards its center, where the degeneration takes place. This procedure can either originate at one definite location of the bundle's periphery with the chaetae subsequently curling up, or formation processes are induced randomly around the bundle followed by the chaetae shifting straight to the center (Fig. 3J, K).

\section{Ultrastructure of scaled capillary chaetae}

The notochaetae of $O$. fusiformis constitute normal capillary structures of an almost perfectly circular shape, with a diameter of average 3-4 $\mu \mathrm{m}$ (Fig. 4A). Each chaeta is subdivided in a distal region densely covered with flat scales, and a proximal region closer to the epidermis with a nearly smooth surface with slight longitudinal grooves (Fig. 4A). Each ridge between two grooves of the proximal part terminates in one scale (Fig. 4A, B). The scales are oriented distally and spiral around the chaeta (Fig. 4A, B). Resembling the shape of a blade, they measure $2-3 \mu \mathrm{m}$ in length and less than $1 \mu \mathrm{m}$ in width (Fig. 4B). The diameter of the distal part decreases constantly towards its tip. The division into both parts occurs in all notochaetae independently from their respective length and thickness (Fig. 4C).

Semi-thin sections of the proximal section show several damaged, disrupted notochaetae (Fig. 3B-D). Transverse sections of capillary chaetae show a typical honeycomblike pattern, with several chitinous canals accumulating to a circular framework (Figs. 3E, 5). The size of the canals 

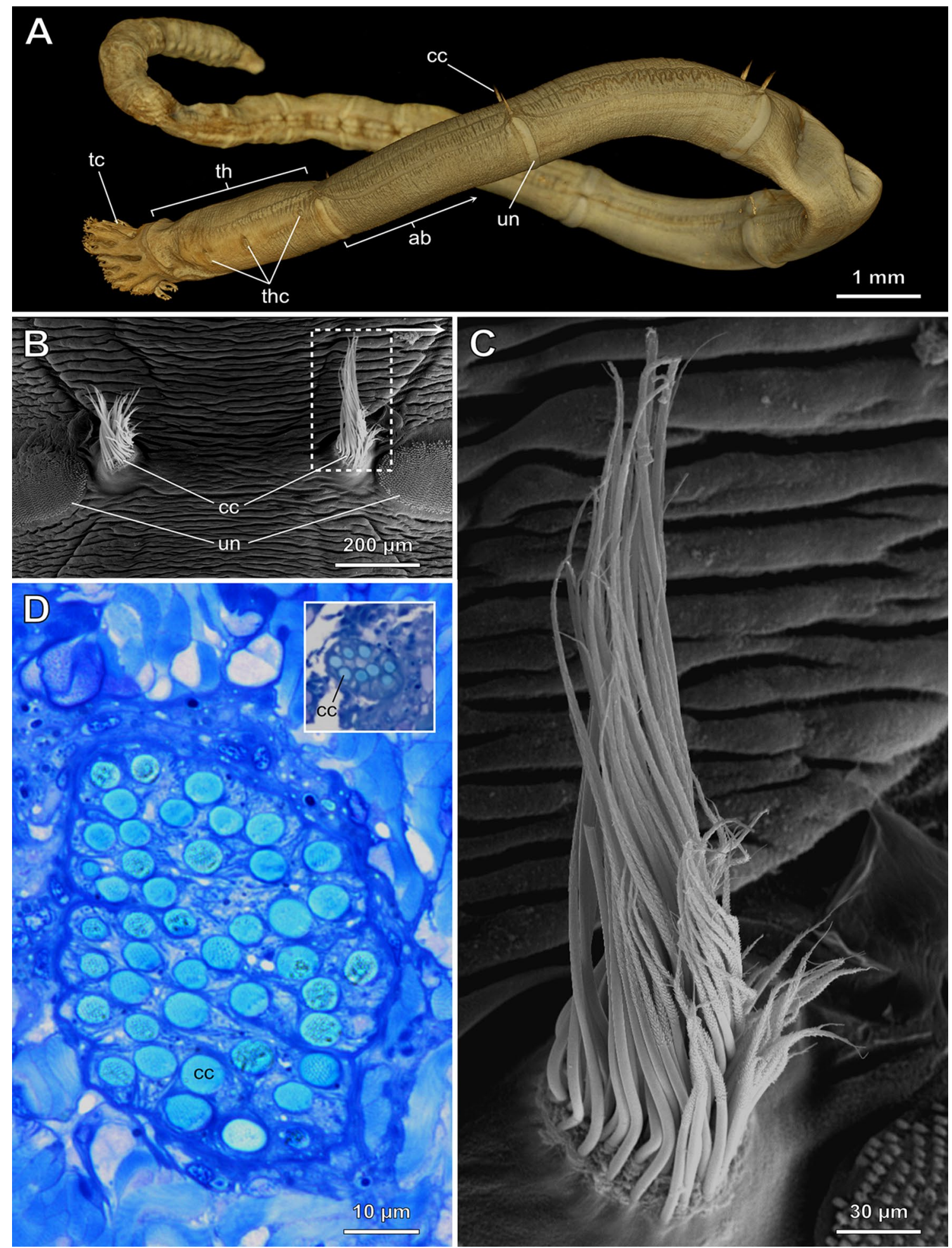

Fig. 1 Owenia fusiformis. A $\mu \mathrm{CT}$-based 3D rendering of $O$. fusiformis, showing all three distinct body parts and indicating the positions of the respective chaetae. B SEM view from dorsal, showing both of the notopodial bundles of capillary chaetae with the beginnings of the neuropodial patches of uncini. C Close-up of the right notochaetal bundle from $(\mathbf{B})$. Note the spiral twist of the bundle. D Semi-thin section of a notochaetal bundle, showing the compact organization of the chaetae. Inlet: Notochaetal bundle of the animal's youngest segment. $a b$ abdomen, $c c$ capillary chaetae, $t c$ tentacle crown, th thorax, thc thoracic chaetae, un uncini 

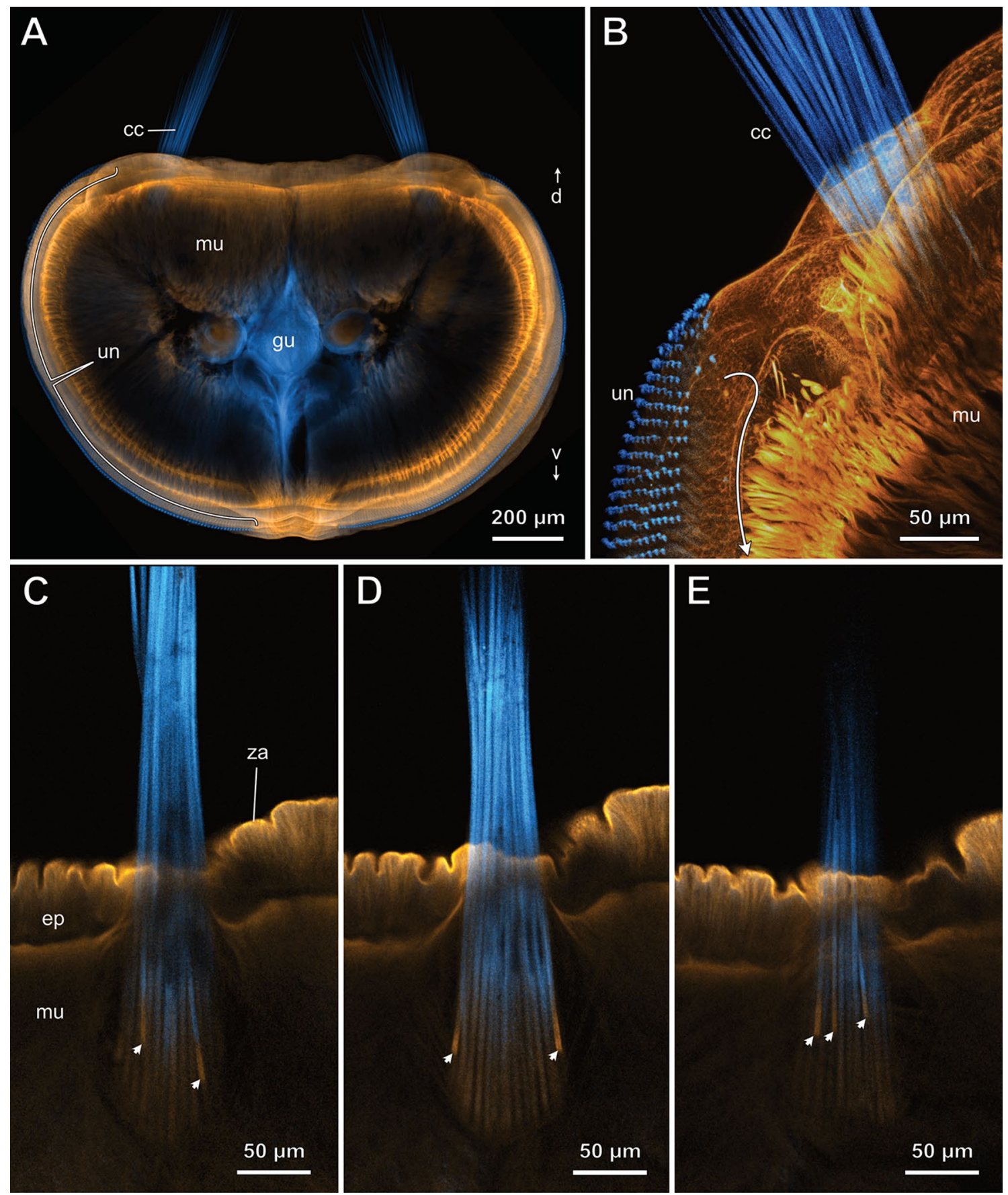

Fig. 2 Confocal z-projections of a phalloidin-stained segment of Owenia fusiformis. A Transverse section, showing both patches of neurochaetae and bundles of notochaetae. B Detailed view of capillary chaetae and dorsal part of the uncinal patch with newly formed hook. C-E Longitudinal sections through a bundle of capillary chae-

does not differ significantly between center and periphery in a newly formed chaeta (Fig. 5A). In some larger and tae, each showing newly formed chaetae. $c c$ capillary chaetae, ep epidermis, $g u$ gut, $m u$ musculature, $u n$ uncini, $z a$ zonula adhaerens, $d$ dorsal, $v$ ventral, arrowheads bases of young chaetae, curved arrow direction, in which uncini shift after formation

older chaetae, a distinct ring of notably smaller canals forms the outermost layer of the framework (Figs. 3E-I, 

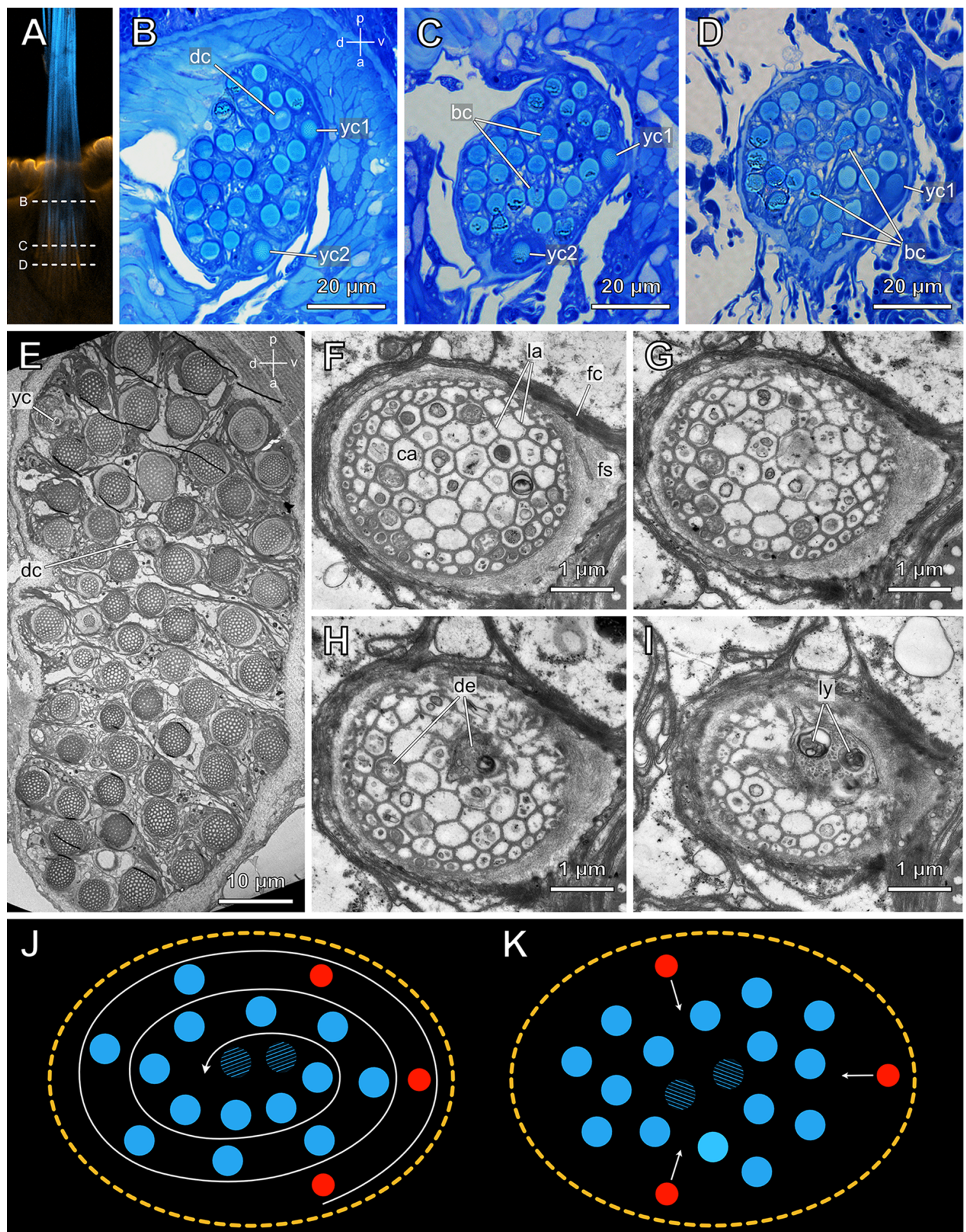

Hypothesis 1

Hypothesis 2

5B). The lamellae of all canals in a chaeta are characterized by a uniform thickness in cross-section. In the longitudinal axis, however, the magnitude of the chitinous meshwork increases by the same extent in the middle as well as in the periphery of each chaeta from distal to proximal (Fig. 5C-E). That way, the chaetae's diameter increases constantly during growth, even though no further canals are added to the meshwork.

Notochaetae in $O$. fusiformis lack any kind of enamel layer. Without such a coating structure, the surface of the 
4Fig. 3 Histological data of the notochaetal sac of Owenia fusiformis. A Confocal z-projection through chaetal bundle. Dashed lines indicate the respective depths of the sections in B-D. B-D Semi-thin toluidine blue stained transverse sections through a bundle with two newly formed chaetae in the periphery of the bundle and one degeneration process. Note the broken chaetae. e TEM transverse section through a bundle of capillary chaetae with one young and one degenerating chaeta. F-I Detailed views of the degeneration process of a chaeta, each a few $\mu \mathrm{m}$ apart. Note the loose follicle. F Degeneration starts at the chaetal periphery. Parts of the disintegrating cell protrude inside the chaetal canals. G Lamellae of the central canals begin to dissolve. H Disintegrating cell breaks through the canal system of the chaeta. I Lysosomes inside of the degenerating cell become visible. Decomposition of follicle cell starts. J, K Two hypotheses about the creation of the chaetal arrangement in the notopodium, illustrated as schematic drawings. J Chaetae are formed in a row, which curls up. K New chaetae are formed all along the periphery of the chaetal bundle and degenerate in its center. $b c$ broken chaeta, $c a$ chaetal canal, $d c$ degenerating chaeta, $d e$ degenerating cell, $f c$ follicle cell, $f s$ follicular space, la chaetal lamella, ly lysosome, yc young chaeta, $a$ anterior, $d$ dorsal, $p$ posterior, $v$ ventral, legend to schemes: yellow dashed line chaetal sac, red dots young chaetae, blue dots old chaetae, shaded blue dots degenerating chaetae, arrows direction of formation

chaeta is not smooth, but grooved and the entire chaeta seems to be composed of a bundle of hollow, chitinous fibers (Figs. 4A, 5B, C). This special surface structure is more evident in the distal section of the proximal, unscaled part of the chaeta, because here the chitinous meshwork is thinner than at the basis (Fig. 5C-E). Some chaetae show an irregular canal pattern with particularly large canals in the periphery (Fig. 5B).

Proximally, the apical membrane of each follicle cell tightly surrounds the chaetae and hemidesmosomes located in the apical membrane of the follicle cells connect their intermediate filaments to the chaeta. These filaments cross the follicle cell and adhere to the basal matrix by hemidesmosomes (Fig. 5B, E). The dynamic microvilli of the chaetoblast with a length of up to $2 \mu \mathrm{m}$ are far more prominent than those of the epidermal cells (Fig. 5A). More distally, some extracellular, amorphous mass is interposed between the adluminal surface of the follicle cell and the chaeta (Fig. 5C). Here, no hemidesmosomes connect follicle cells and chaeta.

The scales of the notochaetae are flat and bend away from the chaetal axis (Fig. 6A). Each scale arises from one hollow chitinous canal the chaeta appears to be composed of. The scales, thus, have a hollow cavity inside that lack an apical pore (Fig. 6B).

\section{Chaetogenesis}

The ultrastructural data on the notochaetae of $O$. fusiformis revealed the details of the formation process that causes subdivision of the chaeta into a distal scaled and proximal smooth part. At the beginning of chaetal formation, the chaetoblast grows constantly, adding radially more and more microvilli and, thus, hollow canals to the chaetal framework (Fig. 6H-K). Due to continuous polymerization of chitin, the chaeta grows constantly, being pushed distally. That way, the radially added hollow canals are shorter than the previously formed ones forming the center of the chaeta. Peripheral addition of canals causes a cone-like chaetal tip (Fig. 4A, C).

Since an enamel is not secreted by the follicle cells, peripheral adding of microvilli during chaetogenesis has another effect. Each new microvillus is rather broad and flat. It is offset from the remaining microvilli of the chaetoblast and initially surrounded by a small portion of the follicle cell. Chitin polymerizes on the surface of a newly formed microvillus and, since this is not connected to the previously formed ones, forms an isolated, slightly flat tip, the prospective scale (Fig. 6C-F). During the further course of chaetogenesis the microvillus enlarges and merges with the previously formed ones. The initially formed tip, however, remains offset from the chaeta and forms one scale of the distal section of the capillary chaeta. At this region, the follicular space is wider so that the offset tips of the scales are not in contact with the surrounding follicle cells. Besides these tips, the follicular space is sporadically filled with some filamentous structures, which emerge from the follicle cells and reach towards the chaeta (Fig. 6G).

Peripheral adding of microvilli is a successive process, during which new microvilli arise radially from the surface of the chaetoblast - a process that causes the scales to spiral across the longitudinal axis of the chaeta (Fig. 4B). The regularity of the scale pattern and the involvement of the follicle cells exclude that the scales are the result of exterior mechanical influences leading to an erosion of the chaetae, but are formed during chaetogenesis. At some point during growth, the chaetoblast stops adding microvilli, with which the final number of canals of each particular chaeta is determined. From here on, the formation of scales is not possible anymore, which means that reaching the final number of microvilli marks the point of the transition between the scaled and the smooth part of the chaeta. Henceforth, a rise of the chaeta's diameter is restricted to an increasing thickness of the chitinous lamellae (Fig. 5C-E).

\section{Discussion}

While the oweniid neuropodial hooks prevent the animal from being pulled out of its sediment tube by predators, the notochaetae's function is not clarified yet (Capa et al. 2019). They differ from the neurochaetae in forming a densely packed bundle with its respective adjacent chaetae being in touch with each other. Here, the scales of the chaetae may show an advantage by reinforcing the chaetal contact within the bundle. Like barbs in bird feathers, the scales exponentiate the possible connection points, increasing the 


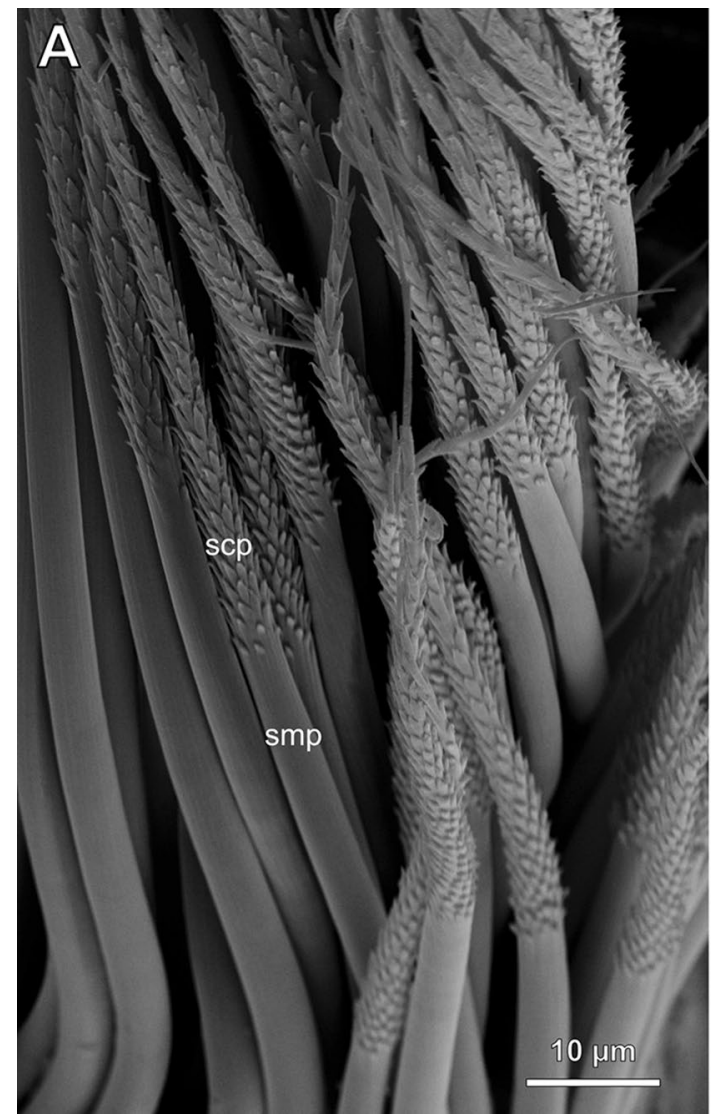

Fig. 4 SEM data of notochaetae of Owenia fusiformis. A Notopodial chaetae with focus on the transition between smooth and scaled part, being located at the same respective length of each chaeta. Notice the slight grooves in the surface of the smooth part, with each ridge culminating in a scale. B Close-up of the scaled part of several chaetae,

grip between the chaetae (Sullivan et al. 2016). Combined with the spiral twist of the chaetae, this explains the compact nature of the bundle.

The anterior thoracic chaetae of Owenia fusiformis have been observed to take part in the burrowing behaviour (Watson 1901). A similar function seems possible for the abdominal notochaetae. Furthermore, they could fulfil a sensory function, giving some feedback about the tube's width during its building process. Tube building maldanids have been observed to show variances in their tubes' diameters depending on the condition of their capillary chaetae (Woodin et al. 2003). Another possibility is an involvement in the animal's irrigation mechanisms. To pump fresh oxygen-rich water through their tubes periodically, annelids perform peristaltic movements (Sendall et al. 1995). Capillary chaetae have been identified to serve as stabilizing elements during these movements to avoid the animal from changing its position within the tube (Merz and Woodin 2006). However, these hypotheses remain speculative and need to be tested experimentally with living specimens.

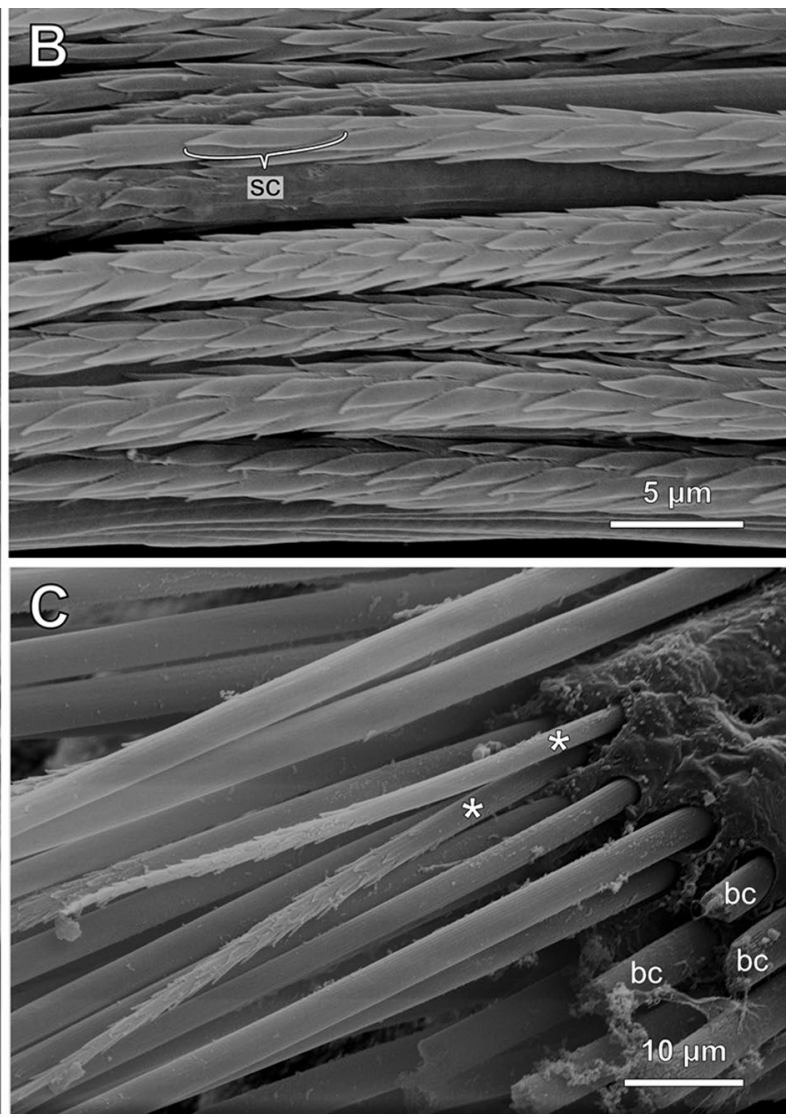

highlighting the blade-like shape of the scales. C Two smaller chaetae, each already subdivided into smooth and scaled part, emerging from the body surface. asterisks small chaetae, $b c$ broken chaetae, $s c$ scale, scp scaled part, smp smooth part

\section{Structure and formation of capillary chaetae}

In transverse sections, a honeycomb-like pattern of empty canals separated by chitinous lamellae characterizes annelid chaetae. In certain cases, this pattern can also be seen at high magnification in the light microscope. The pattern is a remnant of the formation process, the chaetogenesis, during which chitin is continuously deposited between the apical microvilli of the chaetoblast. Empty canals remain where microvilli once stood; the structure of the chaeta largely result from changes of the microvilli pattern during chaetogenesis (Hausen and Bartolomaeus 1998; O'Clair and Cloney 1974). Chaeta thus can be described as a bundle of tightly fused hollow fibers. These are surrounded by an enamel that is secreted by the follicle cells (Hausen 2005). In all annelid chaetae studied thus far, formation of an enamel correlates with vesicles containing homogeneously electron-dense vesicles inside the basalmost follicle cells. These vesicles are formed in a Golgi-stack associated process; the contents are released into the gap between the chaeta and the follicle cell (e.g., Bartolomaeus 1995, 1998; 


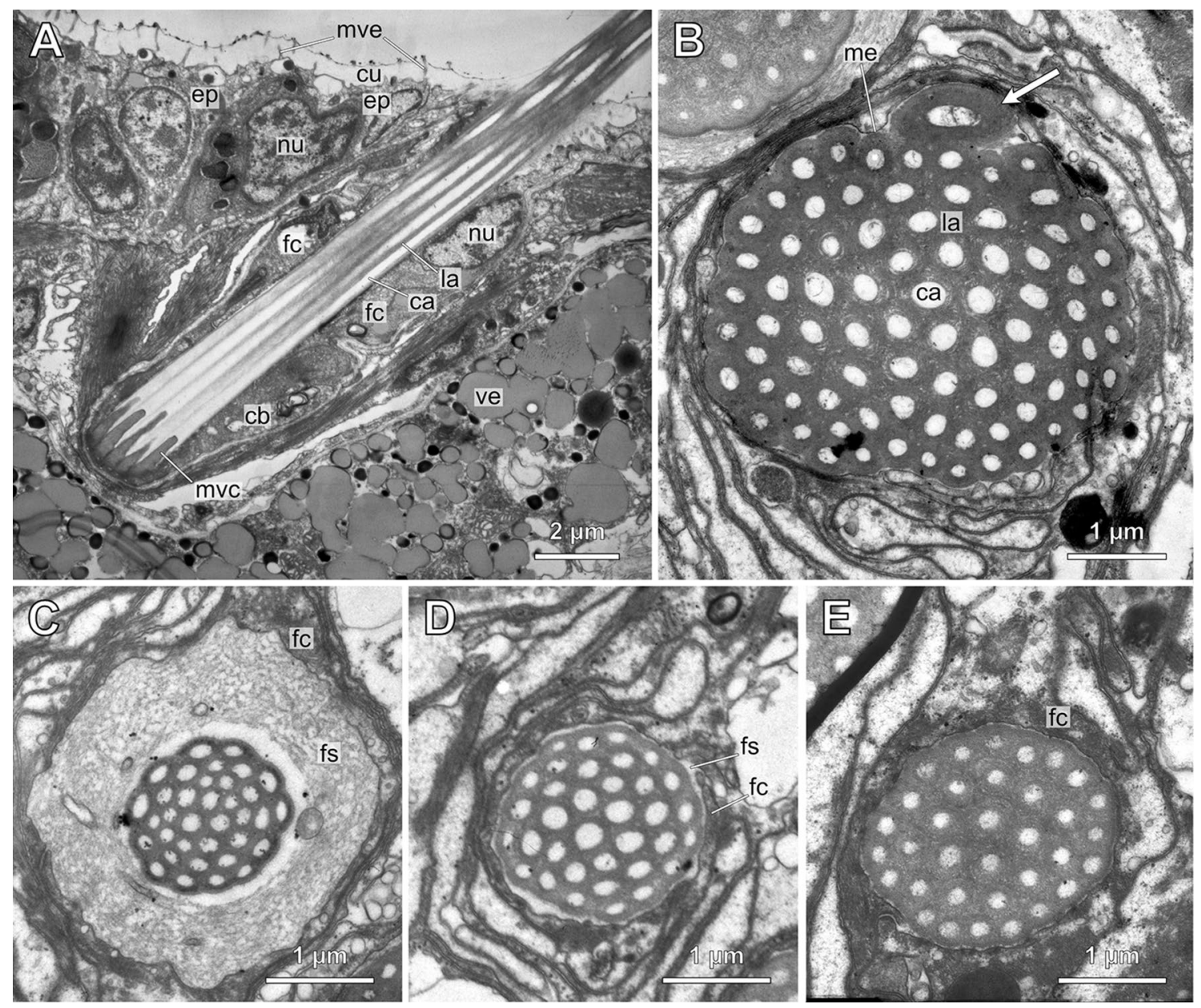

Fig. 5 TEM data of Owenia fusiformis. A Longitudinal section through a newly formed capillary chaeta with basis breaking through the cuticle. B Transverse section through a capillary chaeta with one offset canal. Note the lack of enamel. C-E Three transverse sections through the same capillary chaeta at different heights with variation in follicle width and thickness of chitinous meshwork. $c a$ chaetal canal, $c u$ cuticle, $e p$ epidermal cell, $f c$ follicle cell, $f s$ follicular space, la chaetal lamella, me membrane of follicle cells, $m v c$ microvilli of chaetoblast, mve microvilli of epidermis, $n u$ nucleus, $v e$ vesicles containing glandular secretions, arrow offset canal
Hausen 2005. Tilic et al. 2021a, b: Fig. 4; Tilic et al 2019: Fig. 7B; Tilic et al 2015a, b: Fig. 8). No such vesicles were observed in the follicle cells involved in the formation of capillary chaetae in $O$. fusiformis.

In their simplest construction chaetae, thus, are distally tapering bristles that mechanically resemble glass fiber sticks. Such chaetae are termed capillary chaetae; they can be found in nearly all annelid groups except for Sipuncula (Capa et al. 2019; Merz and Woodin 2006; Weigert and Bleidorn 2016). Transverse sections show wide canals with thin lamellae in the center. The diameter of the canals decreases towards the periphery, while the lamellae become thicker (George and Southward 1973). An outer, chitinous enamel layer surrounds the capillary chaeta (Gustus and Cloney 1973; Lanterbecq et al. 2008; Tilic et al. 2014).

The capillary chaetae of $O$. fusiformis differ from the above described general structure in several aspects. (1)
The canals do not differ significantly in size or shape and their lamellae are equally thick in transverse sections. (2) Each capillary chaeta lacks an enamel layer, so that it seems to consist of a bundle of hollow fibers and shows longitudinal grooves on its surface. (3) The tip and the sub-distal surface are covered by scales that spiral down the chaeta while the diameter of the chaeta increases. The proximal section lacks scales; its diameter is constant all the way down to the follicle.

We interpret the specific structure of the chaetae as derived. The almost identical diameter of the canals in the inner of the chaeta causes high flexibility that is not only in composition but also in mechanics similar to a glass fiber stick. The missing enamel may increase the flexibility of the entire chaeta, but seems to impair their structural integrity. This may explain the unexpectedly high number of broken chaetae found in semi sections-a damage that 

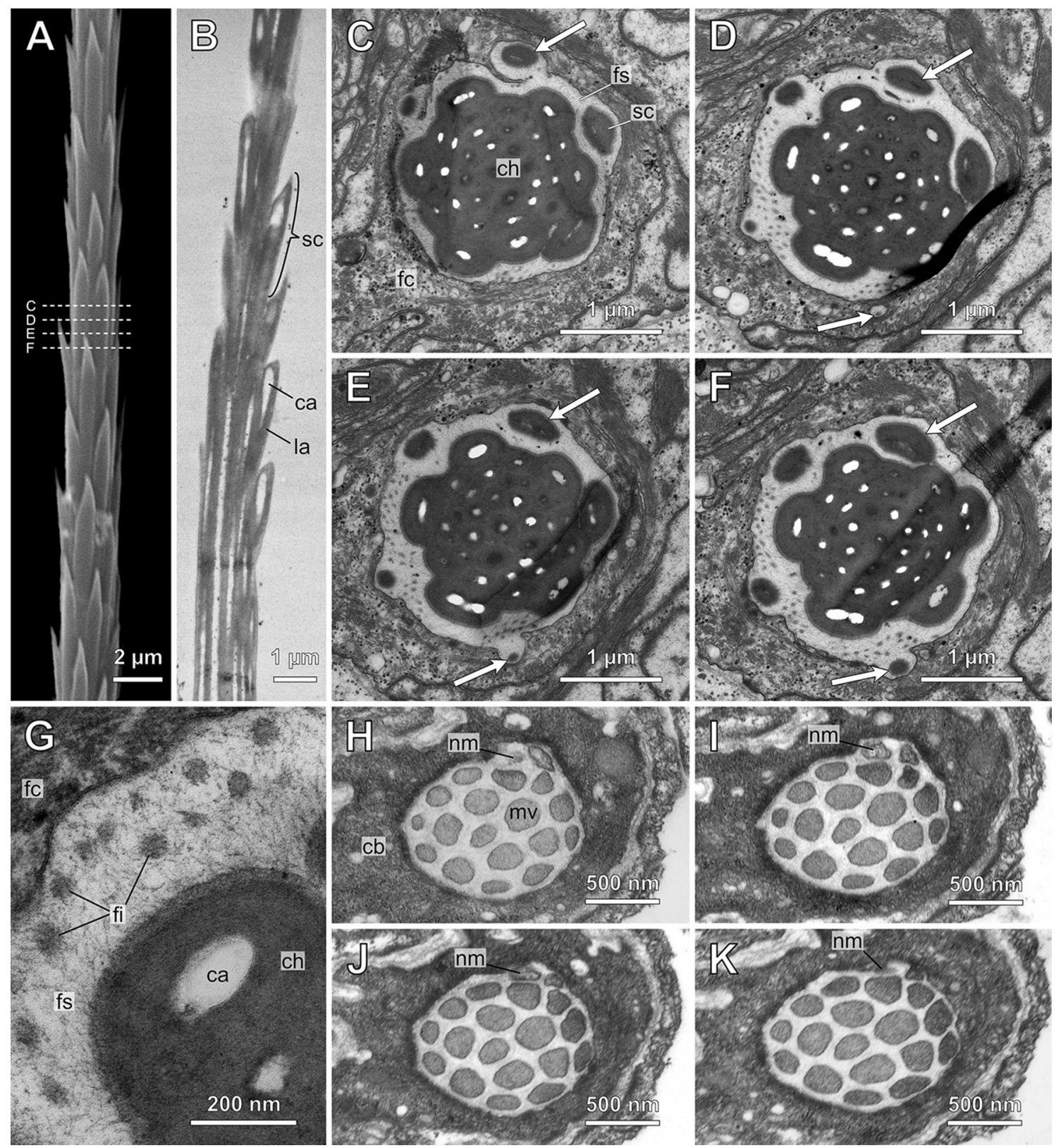

Fig. 6 SEM \& TEM data of Owenia fusiformis. A A single capillary chaeta, showing the scaled part. Dashed lines indicate the positions of the sections in C-F. B Longitudinal section through the scaled part of a capillary chaeta, highlighting the hollow character of the scales. C-F Transverse sections of the scaled part of a chaeta, with distances of $0.5 \mu \mathrm{m}$ to the respective following one. The scales are wrapped by the follicle cell at their tips. G Close-up of the follicular space, containing filamentous structures emerging from the follicle cell. H-K Microvilli brush border of a growing chaetoblast at four different levels $0.5 \mu \mathrm{m}$ apart from each other. Note the addition of a new microvillus in the periphery, which is significantly shorter than the others. $c a$ canal, $c b$ chaetoblast, $c h$ chaeta, $f c$ follicle cell, $f i$ filamentous structure, $f s$ follicular space, la lamella, $m v$ microvillus, $\mathrm{nm}$ new microvillus, $s c$ scale, arrows marking the same two canals in all images to comprehend the interaction between follicle cell and scales of the chaeta is known from Amphinomida, but there it results from calcification (Tilic et al. 2017). The missing enamel is also a prerequisite to see the apical scales that cover the tip of the chaeta. The scales are nothing but the tips of individual hollow fibers the chaeta consists of. Since no enamel coats the scales, the increase in the diameter of a chaeta is simply caused by adding more microvilli peripherally to the group of apical microvilli initially formed by the chaetoblast. The absence of an enamel is not necessarily a primary condition, since such an enamel occurs in the neuropodial hooks of $O$. fusiformis as well as in chaetae of other annelids studies thus far (Meyer and Bartolomaeus 
1996). We presently interpret the absence of an enamel in capillary chaetae as a secondary loss.

The apical part of the capillary chaetae being covered with scales is not a feature solely found in $O$. fusiformis, but is common among oweniid species (Capa et al. 2012; Ford and Hutchings 2005; Koh et al. 2003). We assume that a similar formation process like the one described here for $O$. fusiformis also gives rise to the scales covering the distal section of capillary chaetae in other oweniids. Outside Oweniidae scale-like surface ornamentations can be found in several groups of the Errantia. They may be restricted to one face of the chaetae, like in nephtyid species (Dnestrovskaya and Jirkov 2011) or are hairs or barbs like in aphroditid species. In the latter, they are a modification of the enamel or secretions of the follicle cells that are deposited in the enamel and are formed without the involvement of the chaetoblast (Tilic et al. 2021a, b).

Structure and formation of capillary chaetae in $O$. fusiformis differ from other annelids as the follicle cells are simply involved in shaping the chaeta, but not in providing structural components, like an enamel. Thus far, $O$. fusiformis is an exception to the widely accepted and often confirmed concept that the follicle cells contribute the largest part of chitin during chaetogenesis (Bartolomaeus 1998; Hausen and Bartolomaeus 1998; O'Clair and Cloney 1974; Tilic et al. 2015b).

\section{The formation of chaetal bundles}

During the last decades, it has been shown that chaetal arrangement and position of the formative sites are phylogenetically informative (Hausen 2005; Hoffmann and Hausen 2007; Kieselbach and Hausen 2008; Meyer and Bartolomaeus 1996; Tilic et al. 2015a). In several annelids, chaetae are organized in rows, with one formative site at one end and a degenerative site at the opposite end. This is especially the case in the neuropodia of sedentary annelids (Bartolomaeus 1998). In other groups, though, chaetae are arranged in a compact bundle, which makes it more difficult to comprehend the creation of this pattern. This mainly applies to the capillary notochaetae, which even in those taxa possessing rows of neurochaetae, form bundles when seen from the exterior. Several species of sedentary annelids may serve as an example, among them Terebellidae, Maldanidae, Arenicolidae, Sabellidae and Serpulidae. In the species of these groups, capillary chaetae actually are arranged in a single or a double row, but bundled by the structure of the chaetal sac or curled inside the chaetal sac. In each case, there is a single formative site at one end of the simple or curled row or double row (De Assis and Christoffersen 2011; Hausen and Bleidorn 2006; Knight-Jones 1981; Tilic et al. 2017).

In the case of the capillary chaetae in $O$. fusiformis, no distinct formative site can be identified. New chaetae are formed all along the periphery of the bundle and old ones are degenerated in its middle. Therefore, capillary chaetae are either formed on one end of a curled row so that the older chaetae are moved into the center where they degenerate or they are formed anywhere in the periphery of the chaetal sac and, while getting older, are moved to the center where they degenerate. The structure of the chaetal sac and length of the young chaetae support the former assumption. Newly formed chaetae are short; inside the chaetal sac, they are located closely underneath the epidermis. As it gets older, the chaeta gets longer and expands deeper inside the chaetal sac (Tilic et al. 2015b; Tilic and Bartolomaeus 2016). In $O$. fusiformis, the newly formed chaetae show the same movement while growing. Their peripheral position relative to the remaining chaetae is caused by a spiraled chaetal sac, so that the youngest chaetae lie at the outer margins, older chaetae inner to them and the degenerating, oldest chaetae in the middle.

This interpretation is supported by the structure of the neuropodium in juvenile, just metamorphosed $O$. fusiformis. In contrast to adults which possess large patches of hooked chaetae (Meyer and Bartolomaeus 1996), only a single row with a single formative site is present in the young specimen (supporting information, Fig. S1). We assume that chaetal arrangement in both parapodial rami is basically the same, but altered during growth and development. In the notopodium the row becomes spiraled, while in neuropodia, the row most likely becomes multiplied during ontogenesis (Meyer and Bartolomaeus 1996).

Chaetal bundles with several chaetae being formed simultaneously are known from the neuropodia in Apistobranchidae (Hausen 2005). In this case, however, the formation of chaetae is clearly restricted to the posterior margin of the bundle. This differs from the formation pattern of the notochaetae in $O$. fusiformis, but confirms the presence of a designated formative site as the origin of a chaetal bundle. Large patches of long capillary chaetae can be found in both parapodial rami of Amphinomidae. The neuropodium shows one dorsal formative site, the notopodium a dorsal and a ventral one (Tilic et al. 2017). Here, chaetae are also primarily formed in a row. Based on these results, we presently assume that a single chaetal sac in which the chaetae are arranged as a row, is the primary condition in noto- and neuropodia; any modification of this structure, i.e. curling, multiplication, etc. must be derived.

\section{Degeneration of chaetae}

In contrast to the formation process, the degeneration of annelid chaetae has been rarely studied (Kolbasova et al. 2014). Nonetheless, two different forms of degeneration can be distinguished. In Clymenella torquata (Leidy, 1855), chaetae are deposited within the coelom where degradation 
via coloemocytes takes place (Pilgrim 1977). In Pseudopotamilla reniformis (Bruguière, 1789) and Capitella capitata (Fabricius, 1780), on the other hand, disintegration of chaetae and the surrounding follicle is associated with high numbers of lysosomes within the chaetal sac (Kolbasova et al. 2014; Schweigkofler et al. 1998). The same has been reported for the neurochaetal hooks of $O$. fusiformis (Meyer and Bartolomaeus 1996). They are dissolved in the presence of lysosomes as well, which are located in special cells, probably constituting former chaetoblasts. This complies with our observations concerning the notochaetae of $O$. fusiformis. An additional characteristic of this degeneration process, we can add, is a wide and loose follicle, filled with an amorphous electron light mass.

\section{Conclusion}

The capillary notochaetae of Owenia fusiformis are particular among annelid chaetae in terms of shape and arrangement. The lack of an enamel layer secreted by the follicle cells is unique in annelids and must be considered a derived condition in notochaetae. In the neuropodia of $O$. fusiformis (Meyer and Bartolomaeus 1996: Fig. 4) and in the chaetae of other polychaete species, the basalmost follicle cells contain electron-dense staining, Golgi-processed vesicles that strictly correlate with the presence of an enamel. If this material actually contributed to forming an enamel, its absence in the notopodial chaeta could be explained by the lack of the respective vesicles. Furthermore, our results on the formation of chaetal bundles and the degeneration of chaetae substantiate that one row of chaetae with a single formative and a single degenerative site per parapodial ramus represents the primary condition in annelids. Thus, chaetal bundles likely evolved several times independently. Prior to any further evolutionary consideration, however, chaetal topology and arrangement in Magelonidae, the sister group of Oweniidae, still needs to be studied.

Supplementary Information The online version contains supplementary material available at https://doi.org/10.1007/s00435-021-00547-z.

\begin{abstract}
Acknowledgements We would like to thank the Station Marine de Concarneau for their support in collecting the here examined specimens. We are also grateful to Dr. Gregor Kirfel at the Institute for Cell Biology in Bonn for his support with the use of FEI Verios 460L scanning electron microscope, funded by State of North Rhine-Westphalia and the Deutsche Forschungsgemeinschaft (INST 217/784-1 FUGG). Further thanks are due to Tatjana Bartz for her assistance in laboratory work. The $\mu \mathrm{CT}$-scanner was funded by the State of North Rhine-Westphalia and the Deutsche Forschungsgemeinschaft (INST 217/849-1 FUGG).
\end{abstract}

Funding Open Access funding enabled and organized by Projekt DEAL.
Availability of data and material The examined specimens and histological sections are deposited at the Institute of Evolutionary Biology in Bonn. The reconstructed $\mu \mathrm{CT}$ scan is available as image sequence under https://doi.org/10.5281/zenodo.5222921.

Code availability Not applicable.

\section{Declarations}

Conflict of interest The authors declare that they have no conflict of interest.

Open Access This article is licensed under a Creative Commons Attribution 4.0 International License, which permits use, sharing, adaptation, distribution and reproduction in any medium or format, as long as you give appropriate credit to the original author(s) and the source, provide a link to the Creative Commons licence, and indicate if changes were made. The images or other third party material in this article are included in the article's Creative Commons licence, unless indicated otherwise in a credit line to the material. If material is not included in the article's Creative Commons licence and your intended use is not permitted by statutory regulation or exceeds the permitted use, you will need to obtain permission directly from the copyright holder. To view a copy of this licence, visit http://creativecommons.org/licenses/by/4.0/.

\section{References}

Andrade SC, Novo M, Kawauchi GY, Worsaae K, Pleijel F, Giribet G, Rouse GW (2015) Articulating "Archiannelids": Phylogenomics and annelid relationships, with emphasis on meiofaunal taxa. Mol Biol Evol 32:2860-2875. https://doi.org/10.1093/molbev/msv157

Bartolomaeus T (1995) Structure and formation of the uncini in Pectinaria koreni, Pectinaria auricoma (Terebellida) and Spirorbis spirorbis (Sabellida): implications for annelid phylogeny and the position of the Pogonophora. Zoomorphology 115:161-177. https://doi.org/10.1007/BF00403171

Bartolomaeus T (1998) Chaetogenesis in polychaetous Annelida: significance for annelid systematics and the position of the Pogonophora. Zoology 100:348-364

Bartolomaeus T (2002) Structure and formation of thoracic and abdominal uncini in Fabricia stellaris (Müller, 1774)_Implication for the evolution of Sabellida (Annelida). Zoologischer Anzeiger J Comp Zool 241:1-17. https://doi.org/10.1078/0044-5231-00015

Bartolomaeus T, Meyer K (1997) Development and phylogenetic significance of hooked setae in Arenicolidae (Polychaeta, Annelida). Invertebr Biol 116:227-242. https://doi.org/10.2307/ 3226899

Bartolomaeus T, Purschke G, Hausen H (2005) Polychaete phylogeny based on morphological data-a comparison of current attempts. Hydrobiologia 535:341-356. https://doi.org/10.1007/ s10750-004-1847-5

Beckers P, Helm C, Purschke G, Worsaae K, Hutchings PA, Bartolomaeus T (2019) The central nervous system of Oweniidae (Annelida) and its implications for the structure of the ancestral annelid brain. Front Zool 16:6. https://doi.org/10.1186/ s12983-019-0305-1

Capa M, Parapar J, Hutchings PA (2012) Phylogeny of Oweniidae (Polychaeta) based on morphological data and taxonomic revision of Australian fauna. Zool J Linn Soc 166:236-278. https:// doi.org/10.1111/j.1096-3642.2012.00850.x 
Capa M, Parapar J, Hutchings PA (2019) 4.1 Oweniidae Rioja, 1917. In: Purschke G, Böggemann M, Westheide W (eds) Annelida, vol 1. De Gruyter, Berlin, pp 91-112

Carrillo-Baltodano AM, Seudre O, Guynes K, Martín-Durán JM (2021) Early embryogenesis and organogenesis in the annelid Owenia fusiformis. EvoDevo 12:5. https://doi.org/10.1186/ s13227-021-00176-z

De Assis JE, Christoffersen ML (2011) Phylogenetic relationships within Maldanidae (Capitellida, Annelida), based on morphological characters. Syst Biodivers 9:233-245. https://doi.org/10. 1080/14772000.2011.604358

Dnestrovskaya NY, Jirkov IA (2011) Microscopical studies of nephtyid chaetae (Annelida: Polychaeta: Nephtyidae) from Northern Europe and Arctic. Ital J Zool 78:219-228. https://doi.org/10. 1080/11250003.2011.589175

Ford E, Hutchings PA (2005) An analysis of morphological characters of Owenia useful to distinguish species: description of three new species of Owenia (Oweniidae: Polychaeta) from Australian waters. Mar Ecol 26:181-196. https://doi.org/10.1111/j. 1439-0485.2005.00062.x

George JD, Southward EC (1973) A comparative study of the setae of Pogonophora and polychaetous Annelida. J Mar Biol Ass 53:403-424. https://doi.org/10.1017/S0025315400022359

Gustus RM, Cloney RA (1973) Ultrastructure of the larval compound setae of the polychaete Nereis vexillosa Grube. J Morphol 140:355-366. https://doi.org/10.1002/jmor.1051400308

Hausen H (2005) Chaetae and chaetogenesis in polychaetes (Annelida). Morphol Mol Evol Phylogeny Polychaeta Relat Taxa 179:37-52. https://doi.org/10.1007/1-4020-3240-4_4

Hausen H, Bartolomaeus T (1998) Setal structure and chaetogenesis in Scolelepis squamata and Malacoceros fuliginosus (Spionidae, Annelida). Acta Zool 79:149-161. https://doi.org/10. 1111/j.1463-6395.1998.tb01154.x

Hausen H, Bleidorn C (2006) Significance of chaetal arrangement for maldanid systematics (Annelida, Maldanidae). Scimar 70:7579. https://doi.org/10.3989/scimar.2006.70s375

Helm C, Vöcking O, Kourtesis I, Hausen H (2016) Owenia fusiformis - a basally branching annelid suitable for studying ancestral features of annelid neural development. BMC Evol Biol 16:129. https://doi.org/10.1186/s12862-016-0690-4

Hoffmann S, Hausen H (2007) Chaetal arrangement in Orbiniidae (Annelida, Polychaeta) and its significance for systematics. Zoomorphology 126:215-227. https://doi.org/10.1007/ s00435-007-0042-4

Kieselbach D, Hausen H (2008) Chaetal arrangement provides no support for a close relationship of Sabellidae and Sabellariidae (Annelida). J Morphol 269:104-117. https://doi.org/10.1002/ jmor. 10537

Knight-Jones P (1981) Behaviour, setal inversion and phylogeny of Sabellida (Polychaeta). Zool Scr 10:183-202. https://doi.org/10. 1111/j.1463-6409.1981.tb00495.x

Koh B-S, Bhaud MR, Jirkov IA (2003) Two new species of Owenia (Annelida: Polychaeta) in the northern part of the North Atlantic Ocean and remarks on previously erected species from the same area. Sarsia 88:175-188. https://doi.org/10.1080/0036482031 0001318

Kolbasova GD, Tzetlin AB, Kupriyanova EK (2014) Chaetal loss and replacement in Pseudopotamilla reniformis (Sabellida, Annelida). Invertebr Biol 133:261-273. https://doi.org/10.1111/ivb.12061

Lanterbecq D, Bleidorn C, Michel S, Eeckhaut I (2008) Locomotion and fine structure of parapodia in Myzostoma cirriferum (Myzostomida). Zoomorphology 127:59-68. https://doi.org/10.1007/ s00435-007-0052-2

Limaye A (ed) (2012) Drishti: a volume exploration and presentation tool 8506
Merz RA, Woodin SA (2006) Polychaete chaetae: function, fossils, and phylogeny. Integr Comp Biol 46:481-496. https://doi.org/10. 1093/icb/icj057

Meyer K, Bartolomaeus T (1996) Ultrastructure and formation of the hooked setae in Owenia fusiformis Delle Chiaje, 1842: implications for annelid phylogeny. Can J Zool 74:2143-2153. https:// doi.org/10.1139/z96-243

O'Clair RM, Cloney RA (1974) Patterns of morphogenesis mediated by dynamic microvilli: Chaetogenesis in Nereis vexillosa. Cell Tissue Res 151:141-157. https://doi.org/10.1007/BF00222219

Pilgrim M (1977) The functional morphology and possible taxonomic significance of the parapodia of the maldanid polychaetes Clymenella torquata and Euclymene oerstedi. J Morphol 152:281-302. https://doi.org/10.1002/jmor.1051520302

Rimskaya-Korsakova N, Dyachuk V, Temereva E (2020) Parapodial glandular organs in Owenia borealis (Annelida: Oweniidae) and their possible relationship with nephridia. J Exp Zool (mol Dev Evol) 334:88-99. https://doi.org/10.1002/jez.b.22928

Rouse GW, Fauchald K (1997) Cladistics and polychaetes. Zool Scr 26:139-204. https://doi.org/10.1111/j.1463-6409.1997.tb00412.x

Rousset V, Pleijel F, Rouse GW, Erséus C, Siddall ME (2007) A molecular phylogeny of annelids. Cladistics 23:41-63. https://doi.org/ 10.1111/j.1096-0031.2006.00128.x

Schindelin J, Arganda-Carreras I, Frise E, Kaynig V, Longair M, Pietzsch T, Preibisch S, Rueden C, Saalfeld S, Schmid B, Tinevez J-Y, White DJ, Hartenstein V, Eliceiri K, Tomancak P, Cardona A (2012) Fiji: an open-source platform for biological-image analysis. Nat Methods 9:676-682. https://doi.org/10.1038/nmeth.2019

Schweigkofler M, Bartolomaeus T, von Salvini-Plawen L (1998) Ultrastructure and formation of hooded hooks in Capitella capitata (Annelida, Capitellida). Zoomorphology 118:117-128. https:// doi.org/10.1007/s004350050062

Sendall KA, Fontaine AR, O'Foighil D (1995) Tube morphology and activity patterns related to feeding and tube building in the polychaete Mesochaetopterus taylori Potts. Can J Zool 73:509-517. https://doi.org/10.1139/z95-058

Struck TH (2019) Phylogeny. In: Purschke G, Böggemann M, Westheide W (eds) Annelida. De Gruyter, Berlin, pp 37-68

Struck TH, Schult N, Kusen T, Hickman E, Bleidorn C, McHugh D, Halanych K (2007) Annelid phylogeny and the status of Sipuncula and Echiura. BMC Evol Biol 7:57

Sullivan TN, Pissarenko A, Herrera SA, Kisailus D, Lubarda VA, Meyers MA (2016) A lightweight, biological structure with tailored stiffness: the feather vane. Acta Biomater 41:27-39. https://doi. org/10.1016/j.actbio.2016.05.022

Tilic E, Bartolomaeus T (2016) Structure, function and cell dynamics during chaetogenesis of abdominal uncini in Sabellaria alveolata (Sabellariidae, Annelida). Zool Lett 2:1. https://doi.org/10.1186/ s40851-016-0037-4

Tilic E, Hausen H, Bartolomaeus T (2014) Chaetal arrangement and chaetogenesis of hooded hooks in Lumbrineris (Scoletoma) fragilis and Lumbrineris tetraura (Eunicida, Annelida). Invertebr Biol 133:354-370. https://doi.org/10.1111/ivb.12066

Tilic E, Lehrke J, Bartolomaeus T (2015a) Homology and evolution of the chaetae in Echiura (Annelida). PLoS ONE 10:e0120002. https://doi.org/10.1371/journal.pone.0120002

Tilic E, von Döhren J, Quast B, Beckers P, Bartolomaeus T (2015b) Phylogenetic significance of chaetal arrangement and chaetogenesis in Maldanidae (Annelida). Zoomorphology 134:383-401. https://doi.org/10.1007/s00435-015-0272-9

Tilic E, Pauli B, Bartolomaeus T (2017) Getting to the root of fireworms' stinging chaetae - chaetal arrangement and ultrastructure of Eurythoe complanata (Pallas, 1766) (Amphinomida). J Morphol 278:865-876. https://doi.org/10.1002/jmor.20680

Tilic E, Sermelwall S, Bartolomaeus T (2019) Formation and structure of paleae and chaetal arrangement in Chrysopetalidae 
(Annelida). Zoomorphology 138:209-220. https://doi.org/10. 1007/s00435-019-00435-7

Tilic E, Neunzig N, Bartolomaeus T (2021a) Hairy and iridescent chaetae of the sea mouse Aphrodita (Annelida, Errantia). Acta Zool. https://doi.org/10.1111/azo.12395

Tilic E, Geratz A, Rouse GW, Bartolomaeus T (2021b) Notopodial "spinning glands" of Sthenelanella (Annelida: Sigalionidae) are modified chaetal sacs. Invertebr Biol. https://doi.org/10.1111/ivb. 12334

Watson AT (1901) On the structure and habits of the Polychaeta of the family Ammocharidae. Zool J Linn Soc 28:230-260. https://doi. org/10.1111/j.1096-3642.1901.tb01751.x

Weigert A, Bleidorn C (2016) Current status of annelid phylogeny. Org Divers Evol 16:345-362. https://doi.org/10.1007/ s13127-016-0265-7

Weigert A, Helm C, Meyer M, Nickel B, Arendt D, Hausdorf B, Santos SR, Halanych KM, Purschke G, Bleidorn C, Struck TH (2014)
Illuminating the base of the annelid tree using transcriptomics. Mol Biol Evol 31:1391-1401. https://doi.org/10.1093/molbev/ msu080

Woodin SA, Merz RA, Thomas FM, Edwards DR, Garcia IL (2003) Chaetae and mechanical function: tools no Metazoan class should be without. In: Sigvaldadóttir E, Mackie ASY, Helgason GV, Reish DJ, Svavarsson J, Steingrímsson SA, Guðmundsson $\mathrm{G}$ (eds) Advances in polychaete research. Springer, Netherlands, Dordrecht, pp 253-258

Publisher's Note Springer Nature remains neutral with regard to jurisdictional claims in published maps and institutional affiliations. 